\title{
Effect of micro-notches on fatigue strength of electrodeposited nanocrystalline nickel thin films
}

\author{
Keisuke Tanaka ${ }^{1,}$, Yuta Murase $^{2}$, and Hirohisa Kimachi ${ }^{2}$ \\ ${ }^{1}$ Research Department, Nagoya Industrial Science Research Institute, Yotsuya-dori, Chikusa-ku, Nagoya, 464-0819, Japan \\ ${ }^{2}$ Mechanical Engineering Department, Meijo University, Shiogamaguchi, Tempaku-ku, Nagoya, 468-8502, Japan
}

\begin{abstract}
The effect of micro-notches on the fatigue strength of nickel thin films was studied. Two types of thin films with $10 \mu \mathrm{m}$ thickness were produced by electrodeposition using sulfamate solution without and with brightener: ultra-fine grained film (UFG) with the grain size of $384 \mathrm{~nm}$ and nano-crystalline grained film (NCG) with that of $17 \mathrm{~nm}$. Micro-sized notches introduced by FIB had the width of $2 \mu \mathrm{m}$ and various depths from 8 to $150 \mu \mathrm{m}$. Fatigue tests were conducted under the stress ratio of 0.1 . The fatigue strength decreased with increasing depth of notches. NCG had much higher strength than UFG compared at the same notch depth. Notches as small as $8 \mu \mathrm{m}$ did reduce the fatigue strength of both UFG and NCG. The fatigue limit was controlled by the initiation of cracks and no non-propagating crack was observed in specimens fatigued below the fatigue limit. A model of fictitious crack successfully predicted the reduction of the fatigue limit due to micro-notches. The characteristic crack length of NCG was much smaller than the UFG, while the fatigue strength of defect-free NCG was larger than that of UFG. SEM observation of fracture surfaces was conducted to reveal micromechanisms of fatigue crack initiation.
\end{abstract}

\section{Introduction}

Nickel thin films have been used as structural materials for MEMS (micro-electro-mechanical systems) devices made by LIGA process. To improve the fatigue strength of metallic thin films, nanocrystallization is one of the most promising technique. In our previous studies, freestanding nickel thin films with various grain sizes were produced by electrodeposition using sulfamate solution under constant current by changing brightener content [1-3]. The mean grain size measured by TEM ranged from 384 to $17 \mathrm{~nm}$ [4]. The fatigue strength was improved in finer-grained films, following the HallPetch relation. On the other hand, the resistance to fatigue crack propagation got lower for finer grain sizes [1-3,5], suggesting the increase of notch sensitivity by reducing the grain size. The effect of stress consentaration on the fatigue strength of nanocrystalline nickel need to be studied, because fatigue fracture may start at defects or notches in MEMS devices.

In this paper, the effect of micro-notches on fatigue strength reduction was studied by using two types of electrodeposited nickel thin films with the grain size of 384 and $17 \mathrm{~nm}$.

\section{Experimental procedure}

Nickel thin films were produced by electrodeposition using sulfamate solution [1-3]. A polished stainless steel plate was used for a cathode and a pure nickel plate for an anode. Two deposition conditons were adapted : one was without brigtener (sodium allylsulfamate) and the other with brigtener of the amount of $2 \mathrm{~g} / \mathrm{L}$. The temperature of the bath was kept constant at $328 \mathrm{~K}$ for the former case and $313 \mathrm{~K}$ for the latter using a hot-water circulating bath. The $\mathrm{pH}$ value of the solution was maintained at 3.7 to 4.2 by adding sulfamate acid. The solution was stirred by a magnetic stirrer to avoid pit formation. The current density was kept constant at 25 $\mathrm{mA} / \mathrm{cm}^{2}$ by using a constant current supply, and the deposition period was $28 \mathrm{~min}$. The thickness of the thin film was around $10 \mu \mathrm{m}$. After deposition, thin films were removed from the cathode and subjected to the characterization of the tensile and fatigue properties as free-standing films.

The grain size was measured by TEM. The one without brigtener, UFG, had the grain size of $384 \mathrm{~nm}$ and the grain orientation of 100 fiber texture, while the other with brigtener, NCG, had that of $17 \mathrm{~nm}$ and randam grain orientation [4]. The tensile properties and

Table 1 Mechanical properties of UFG and NCG.

\begin{tabular}{c|c|cccc|c}
\hline Material & $\begin{array}{c}\text { Grain size } \\
d, \mathrm{~nm}\end{array}$ & $\begin{array}{c}\text { Youngs } \\
\text { modulus } \\
E, \mathrm{GPa}\end{array}$ & $\begin{array}{r}\text { Yield } \\
\text { stress } \\
\sigma_{0.2}, \mathrm{MPa}\end{array}$ & $\begin{array}{c}\text { Tensile } \\
\text { strength } \\
\sigma_{\mathrm{B}}, \mathrm{MPa}\end{array}$ & $\begin{array}{c}\text { Fracture } \\
\text { strain } \\
\varepsilon_{f}, \%\end{array}$ & $\begin{array}{c}\text { Vickers } \\
\text { hardness } \\
H v\end{array}$ \\
\hline UFG & 384 & 147 & 593 & 887 & 3.1 & 230 \\
\hline NCG & 17 & 182 & 1363 & 2165 & 3.3 & 681 \\
\hline
\end{tabular}


Vicker hardness of two films are summarized in Table 1. NCG with nanosized grains has much higher strength than UFG with ultra-fine grains. The Youngs modulus of UFG is lower than taht of NCG, because of 100 fiber texture.

Figure 1(a) shows smooth sepcimens (SM) made from electrodeposited films by buffing [2]. They have a small stress concetration factor of 1.043 at the centarl region. Micro-notches were introduced with FIB (Focused ion beam) at the the central region A as shown in Fig. 1(b). The notch width was $2 \mu \mathrm{m}$ and the notch tip was square-shaped with a corner radius of $0.20 \mu \mathrm{m}$. The notch length was $8,20,50,120$, and $150 \mu \mathrm{m}$, and the specimens with these lengths are named MN8, MN20, MN120 and MN150, respectively.

Fatigue tests were conducted in a servoelectromagnetic fatigue testing machine (Shimadzu MMT-100N-10) under the stress ratio of $R=0.1$ at a frequency of $20 \mathrm{~Hz}$. The range of the gross stress in the minimum cross section (without micro-notch) was used to express the loading condition. The initiation and propagation of fatigue cracks was observed with a digital microscope during fatigue tests. After specimens were broken, SEM observation was conducted on the fatigue fracture surface and also the exact value of the specimen thickness was measured.

The stress intensity factor (SIF) for a single edge crack of length $a$ in smooth specimens shown in Fig. 1(a) was calculated by the finite element method. The SIF value was expressed by

$$
K=\sigma \sqrt{\pi a} \cdot F(a / W)
$$

$F(\xi)=1.1697-0.2703 \xi+4.235 \xi^{2}-6.049 \xi^{3}+4.293 \xi^{4}$

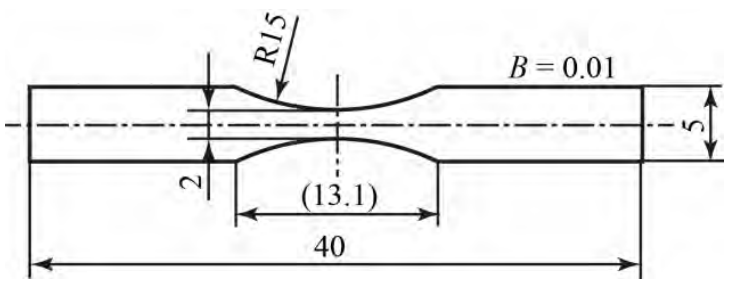

(a) Smooth specimen (SM).
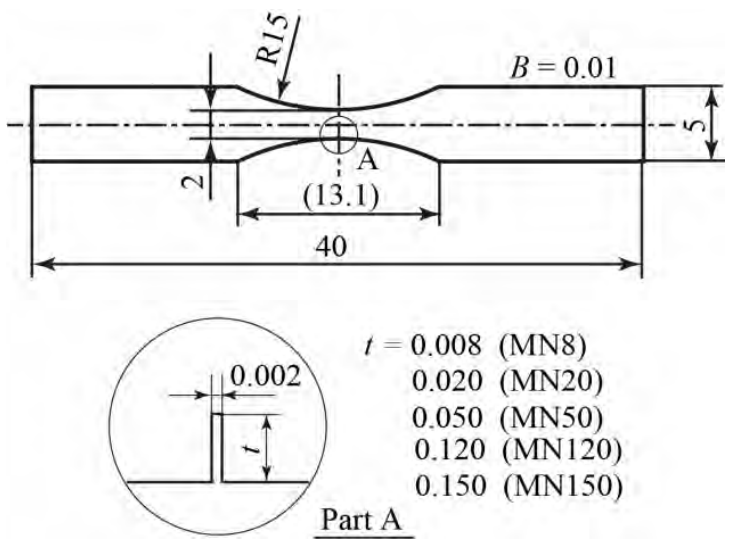

(b) Micro-notched specimen (MN).

Fig. 1 Smooth specimen and micro-notched specimen where $\sigma$ is the gross stress and $W$ is the specimen width, and $\xi=a / W . F$ is the correction factor. For $a=0, F=$ $1.1215 \times 1.043=1.1697$.

\section{Experimental results}

\section{1. $S-N$ relation}

The $S-N$ relation of UFG is shown in Fig. 2, where the gross stress range was taken as the ordinate. The data with the rightward arrow indicate the results for a specimen which was not fractured. The fatigue strength of smooth specimen (SM) was highest, and decreases with increasing notch depth.

Table 2 summarize the fatigue limit, $\Delta \sigma_{w}$, defined by the fatigue life of $10^{7}$ cycles. The stress intensity factor was calculated from the fatigue limit by assuming the notch depth equal the crack depth $a$ in Eq. (1). The equivalent crack length, $a_{\text {eq }}$, indicated in the table is the half crack length converted to an isolated crack which is calculated from

$$
\Delta K_{\mathrm{th}}=\Delta \sigma_{w} \sqrt{\pi a} \cdot F=\Delta \sigma_{w} \sqrt{\pi a_{e q}}
$$

Therefore

$$
a_{e q}=a \cdot F^{2}
$$

The $\Delta K_{\text {th }}$ value of UFG is not constant and decreases with decreasing the notch depth.

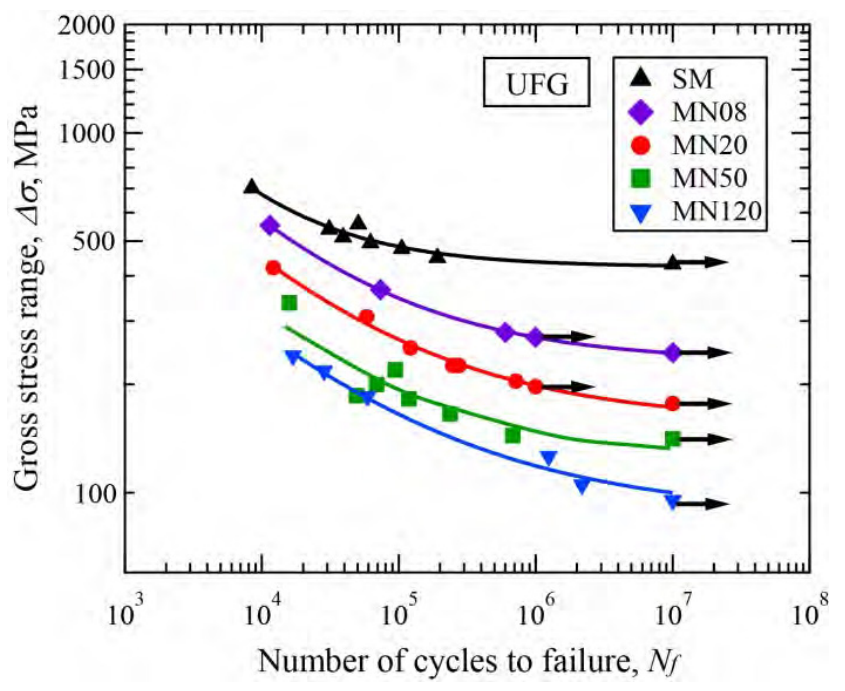

Fig. $2 S-N$ relation of UFG.

Table 2 Fatigue thresholds of UFG.

\begin{tabular}{c|cc|cc}
\hline $\begin{array}{c}\text { Specimen } \\
\text { UFG }\end{array}$ & $\begin{array}{c}\text { Notch length } \\
t, \mu \mathrm{m}\end{array}$ & $\begin{array}{c}\text { Equivalent } \\
\text { lenpth, } a_{\mathrm{cq}}, \mu \mathrm{m}\end{array}$ & $\begin{array}{c}\text { Fatigue limit } \\
\Delta \sigma_{\mathrm{w}}, \mathrm{MPa}\end{array}$ & $\begin{array}{c}\mathrm{SIF}, \Delta K_{\mathrm{th}} \\
\mathrm{MPam}^{\mathrm{I} / 2}\end{array}$ \\
\hline SM & 0 & 0 & 432 & $\mathrm{n} / \mathrm{a}$ \\
\hline MN08 & 8 & 10.8 & 263 & 1.53 \\
MN20 & 20 & 27.0 & 193 & 1.76 \\
MN50 & 50 & 67.6 & 143 & 2.08 \\
MN120 & 120 & 163.7 & 107 & 2.28 \\
\hline
\end{tabular}




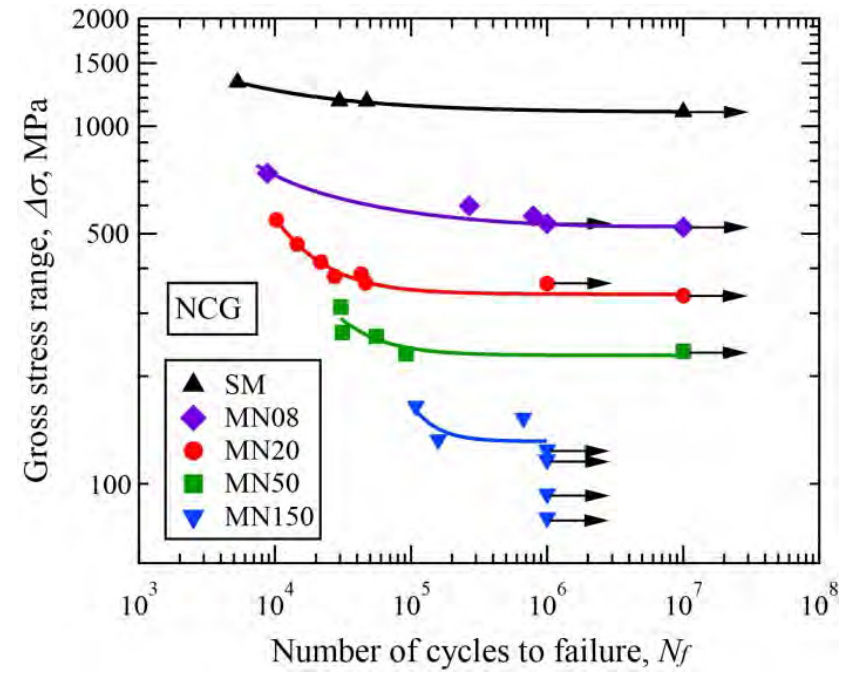

Fig. $3 S-N$ relation of $\mathrm{NCG}$.

Table 3 Fatigue thresholds of NCG.

\begin{tabular}{c|cc|cc}
\hline $\begin{array}{c}\text { Specimen } \\
\text { NCG }\end{array}$ & $\begin{array}{c}\text { Notch length } \\
t, \mu \mathrm{m}\end{array}$ & $\begin{array}{c}\text { Equivalent } \\
\text { lenpth, } a_{\mathrm{eq}}, \mu \mathrm{m}\end{array}$ & $\begin{array}{c}\text { Fatigue limit } \\
\Delta \sigma_{\mathrm{w}}, \mathrm{MPa}\end{array}$ & $\begin{array}{c}\mathrm{SIF}, \Delta K_{\text {th }} \\
\mathrm{MPam}^{1 / 2}\end{array}$ \\
\hline SM & 0 & 0 & 1096 & $\mathrm{n} / \mathrm{a}$ \\
MN08 & 8 & 10.8 & 541 & 3.16 \\
MN20 & 20 & 27.0 & 359 & 3.30 \\
MN50 & 50 & 67.6 & 232 & 3.39 \\
MN150 & 150 & 206 & 129 & 3.27 \\
\hline
\end{tabular}

Figure 3 shows the $S-N$ relation of NCG. The fatigue strength of NCG is much higher than that of UFG, and decreases with increasing notch depth. $S-N$ curves have a rather clear knee at stress cycles of about $10^{5}$ to $10^{6}$ cycles. Table 3 summarizes the fatigue limit at life of $10^{7}$ cycles. The fatigue limit of NCG is much higher than that of UFG when compared at the same notch depth. The threshold stress intensity factor, $\Delta K_{\text {th }}$, is nearly constant for all notch depths.

\subsection{Fatigue crack initiation and propagation}

The initiation and propagation of fatigue crack at the notch root was observed by video recording during fatigue tests. For fatigued specimens run out of $10^{7}$, no non-propagating crack was observed near the notch root for both UFG and NCG. The fatigue limit given in Tables 2 and 3 corresponds to the threshold of crack initiation.

Figure 4 shows fatigue cracks observed by video recording. The arrow indicates the notch tip. The crack length is $50 \mu \mathrm{m}$ for both UFG and NCG. The crack propagates straight perpendicular to the loading direction. The crack in NCG is very fine, while that in UFG is thick indicating the larger amount of plastic deformation associated with crack propagation. The minimum crack length that can be resolved by our video recording system was $10 \mu \mathrm{m}$. Therefore, the crack initiation life was defined as the number of cycles up to the detection of a $10 \mu \mathrm{m}$ long crack. Crack propagation curves were obtained after the initiation of $10 \mu \mathrm{m}$ crack. The rate was calculated by the second method.

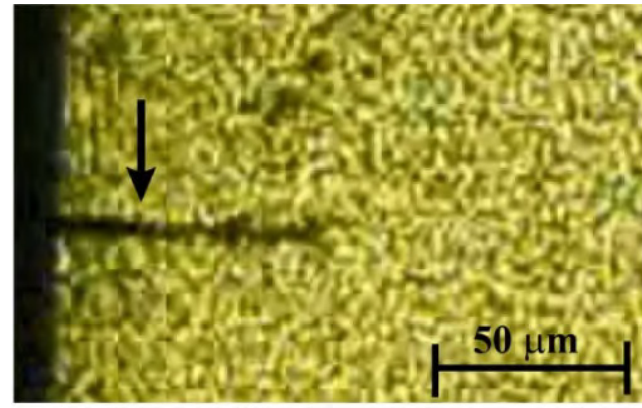

(a) UFG, MN20, $\Delta \sigma=542 \mathrm{MPa}, c=50 \mu \mathrm{m}$ $N=6202, N_{f}=10992$

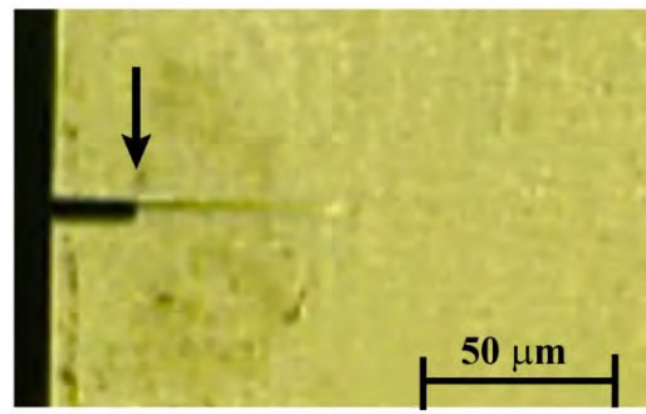

(b) NCG, MN20, $\Delta \sigma=308 \mathrm{MPa}, c=50 \mu \mathrm{m}$ $N=40627, N_{f}=58131$

Fig. 4. Video recorded micrographs of cracks in MN speciemns of UFG and NCG.

The relation between $d a / d N$ and the range of stress intensity factor, $\Delta K$, for UFG and NCG is presented in Figs. 5 and 6, respectively, where $\Delta K$ is calculated by inserting the crack length plus the notch depth for $a$ in Eq. (1). The open marks indicate the data obtained under small-scale yielding (SSY) conditions, while the solid marks are those under large-scale yielding conditions. The all data for NCG satisfy the SSY, and some of UFG at large $\mathrm{K}$ values do not.

The relation obtained for a long crack by loadshedding method is also shown with the small dots in the figures in the figure [6]. The threshold stress intensity factor for propagation of long cracks, $\Delta K_{\text {tho }}$, was 4.26 $\mathrm{MPam}^{1 / 2}$ for UFG and $2.19 \mathrm{MPam}^{1 / 2}$ for NCG. The crack path of NCG was very straight and not accompanied by plastic deformation near crack tips. There might be no extrinsic shielding of the crack tip, the threshold value of $2.19 \mathrm{MPam}^{1 / 2}$ is equal to the effective threshold. The threshold value of $4.26 \mathrm{MPam}^{1 / 2}$ for UFG is larger than that of NCG is mainly due to crack closure, increasing in proportion of the square root of the grain size [6].

For UFG shown in Fig. 5, the $\Delta K$ value of small cracks just after initiation is below the threshold of long crack, 4.26 $\mathrm{MPam}^{1 / 2}$, and then the relation gradually merges to that of long cracks. There is no dip in the crack propagation relation, suggesting non-existence of crack arrest usually observed in sharply notched steel specimens [7]. On the other hand, for the case of NCG as shown in Fig. 6, the $\Delta K$ value of small cracks just after initiation is above the long crack threshold, 2.19 $\mathrm{MPam}^{1 / 2}$, and then the relation between $d a / d N$ and $\Delta K$ for small cracks follows the relation of long cracks. 


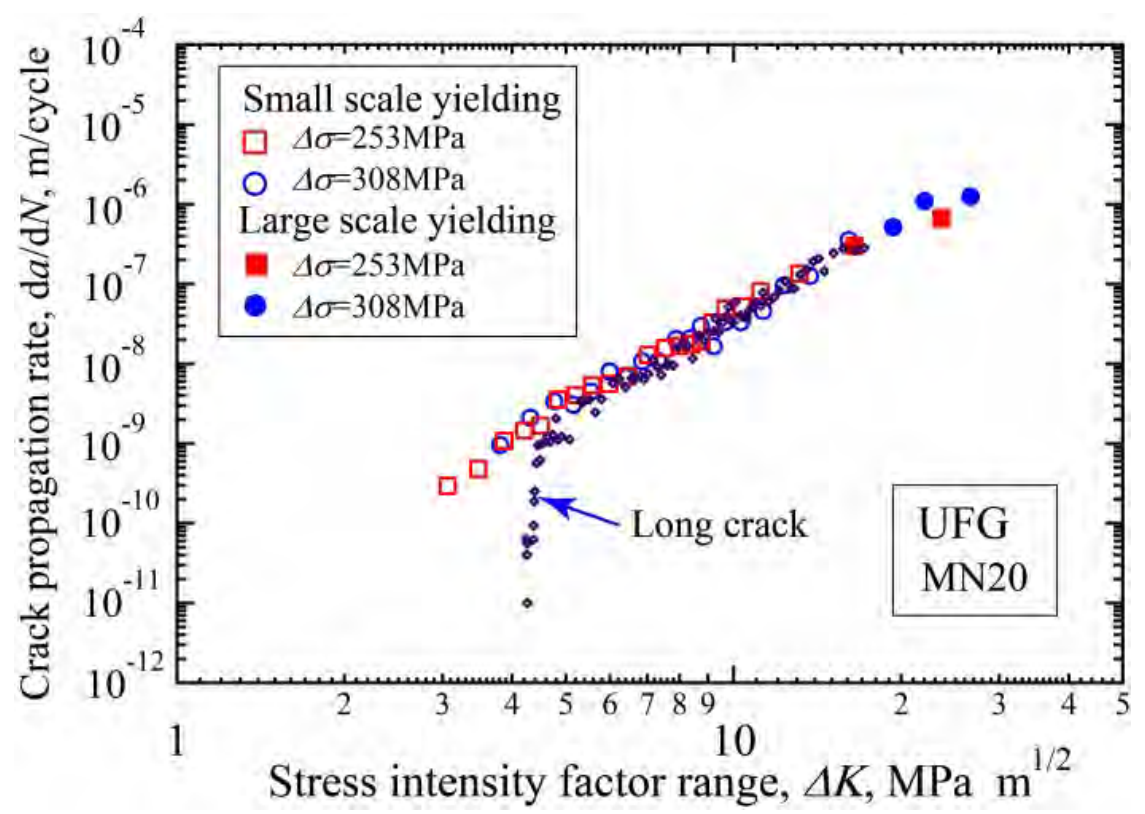

Fig. 5. Relation between fatigue crack propagation rate and stress intensity range of UFG.

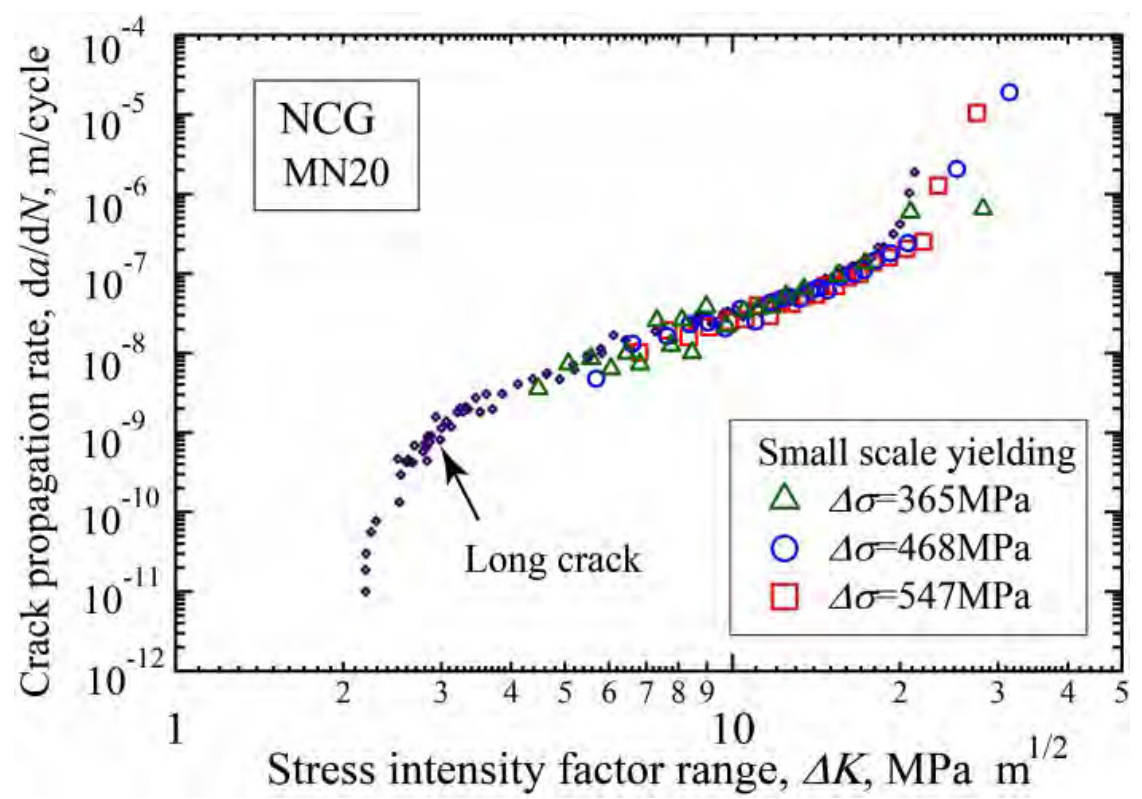

Fig. 6. Relation between fatigue crack propagation rate and stress intensity range of NCG.

\subsection{SEM observation of fatigue fracture surfaces}

SEM micrographs of fatigue fracture surfaces near the notch tip are shown in Fig. 7, where (a) is for MN50 of FG and (b) is for MN20 of NCG. For micro-notched specimens of UFG and NCG, there is no defect near the notch root. The fracture surface of UFG is rather rough and several parallel lines are seen across the thickness, corresponding the columnar grain structure made by electrodeposition. On the other hand, the fracture surface of NCG is very smooth and tiny granular patterns are observed. Cracks are expected to start at the central part of the notch root.
The fatigue fracture surface of SM specimens were also examined by SEM. Material defects were observed at the crack initiation site in SM specimens of NCG, while no defects were seen on the fracture surface of those of UFG. Figure 8 shows two examples of such defects seen on the fracture surface of SM specimens of NCG. Dotted lines in Fig. 8 indicate the boundary of defect areas. Defects made during electrodeposition gave rise to the crack initiation site, and reduced the fatigue strength of NCG even if SM specimens were supposed to be smooth or defect-free. Therefore, the true fatigue limit of defect-free NCG would be higher as discussed later. 


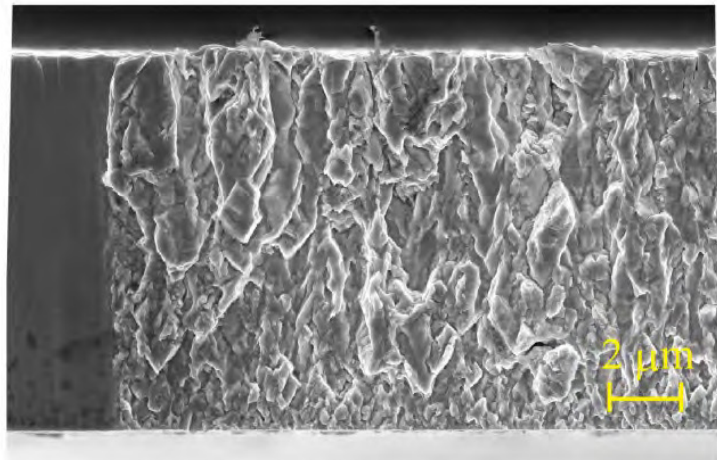

(a) UFG, MN50, $\Delta \sigma=200 \mathrm{MPa}, N_{f}=68793$

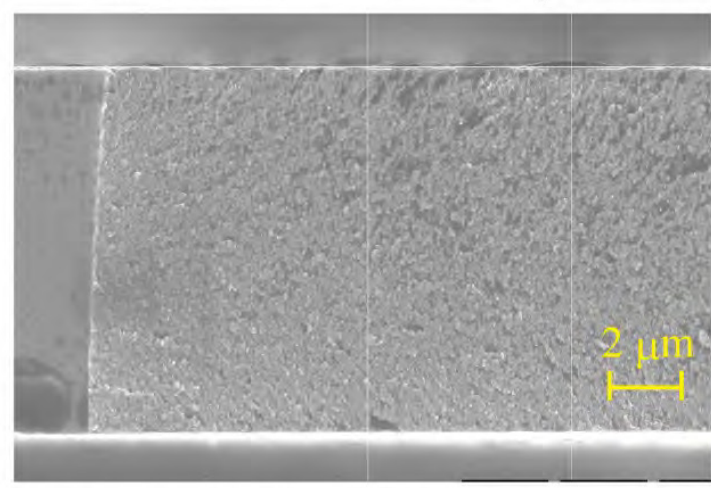

(b) NCG, MN20, $\Delta \sigma=468 \mathrm{MPa}, N_{f}=14528$

Fig.7 SEM micrographs of fatigue fracture surafce near the micro-notch root. The crack propagation rate is from left to right.

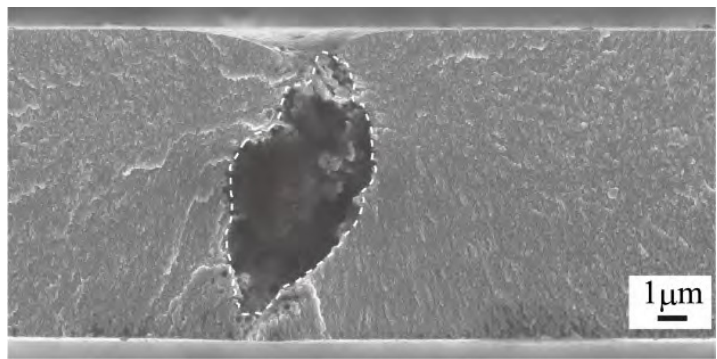

(a) NCG, SM, $\Delta \sigma=1348 \mathrm{MPa}, N_{f}=5290$

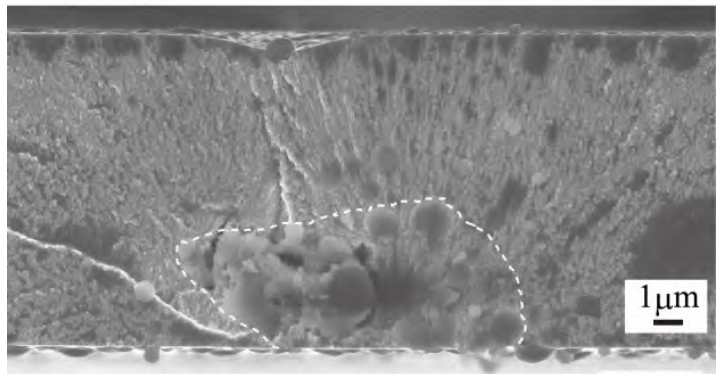

(b) NCG, SM, $\Delta \sigma=1175 \mathrm{MPa}, N_{f}=47266$

Fig.8 SEM micrographs of fatigue fracture surafce of SM specimens of NCG. The dotted area indictes the boundary of defects made by electrodepostion.

\section{Prediction of fatigue strength reduction due to micronotchs.}

\subsection{Fictitious crack model}

In sharply notched specimens, fatigue fracture is not controlled by the maximum stress alone, but by stress acting over a characteristic distance ahead of the notch tip. The fictitious crack model proposed by El Haddad et al [8] is a simple reconciliation for such microstructural influences. The fatigue fracture is assumed to be determined by the condition of the propagation of a fictitious crack existing ahead of the tip of pre-cracks or notches. This model was applied to the prediction of the effect of pre-crack length on the threshold of fatigue crack propagation by Tanaka et al [9]. The model is applied to the present experimental results. The essence of the model is described below.

For an isolated pre-crack with half length $a$ in an infinite plate, the threshold stress, $\Delta \sigma_{w}$, is given by the following condition of crack extension:

$$
\Delta K_{\text {thoo }}=\Delta \sigma_{w} \sqrt{\pi\left(a+a_{0}\right)}
$$

where $\Delta K_{\text {thoo }}$ is the threshold stress intensity factor for long cracks, and $a_{0}$ is the length of the fictitious crack which is determined from the fatigue limit of defect-free specimens, $\Delta \sigma_{w 0}$, as

$$
a_{0}=\left(\Delta K_{\text {thoo }} / \Delta \sigma_{w 0}\right)^{2} / \pi
$$

where $\Delta \sigma_{w 0}$ is the fatigue limit of un-notched defect-free specimens. From Eqs. (3) and (4), the following equation is derived

$$
\Delta \sigma_{w} / \Delta \sigma_{w 0}=\left[a_{0} /\left(a+a_{0}\right)\right]^{1 / 2}
$$

The threshold SIF of short crack, $\Delta K_{\mathrm{th}}$, is

$$
\Delta K_{\text {th }} / \Delta K_{\text {the }}=\left[a /\left(a+a_{0}\right)\right]^{1 / 2}
$$

The threshold condition of pre-cracked specimens gradually changes from $\Delta \sigma_{w}=\Delta \sigma_{\mathrm{w} 0}$ for un-cracked specimens to $\Delta K_{\text {th }}=\Delta K_{\text {tho }}$ for long pre-crack. The $a_{0}$ length is a parameter to distinguish short and long cracks.

To apply the fictitious crack model to single edge notches, the characteristic crack length is often determined by [7]

$$
c_{0}=\left(\Delta K_{\text {tho }} / 1.1215 \Delta \sigma_{w 0}\right)^{2} / \pi
$$

The relation between $c_{0}$ and $a_{0}$ is

$$
c_{0}=a_{0} / 1.1215^{2}=0.795 a_{0}
$$

\subsection{Fatigue threshold of ultra-fine grained films}

The characteristic crack length $a_{0}$ of UFG is determined from Eq. (4) by using the crack initiation threshold SIF value, $\Delta K_{\text {th }}=2.28 \mathrm{MPam}^{-1 / 2}$, of MN120 of UFG shown in Table 2 and the fatigue limit of SM specimen, $\Delta \sigma_{w 0}=$ $432 \mathrm{MPa}$, multiplied by the stress concentration factor of 1.043. The multiplication is required to obtain the fatigue limit of un-notched specimens, $\Delta \sigma_{w 0}{ }^{*}$, because SM specimens have small stress concentration of 1.043. The value of $\Delta \sigma_{w 0}{ }^{*}$ is used for $\Delta \sigma_{w 0}$ to calculate $a_{0}$ and $c_{0}$ 
values. Table 4 summarizes the values. They are about 20 times the grain size.

Figure 9 shows the relation between the threshold stress, $\Delta \sigma_{w}$, and the equivalent depth, $t_{e q}$, where the open marks indicate specimens not fractured and the solid marks indicate those fractured. The dotted line corresponds the relation of Eq. (5) predicted by using the parameters given in Table 4. The prediction agrees very well with the experimental data. Figure 10 shows the change of SIF with the notch length, where the dotted line indicates the prediction by Eq. (6). The decrease of $\Delta K_{\text {th }}$ for shorter notches is well predicted by Eq. (6).

Table 4 Charctersitic crack length of UFG and NCG.

\begin{tabular}{c|c|cc|cc}
\hline & $\begin{array}{c}\text { Threshold } \\
\text { SIF }\end{array}$ & \multicolumn{2}{|c|}{ Fatigue limt } & \multicolumn{2}{c}{$\begin{array}{c}\text { Characteristic } \\
\text { crack length }\end{array}$} \\
& $\begin{array}{c}\Delta K_{\text {th }} \\
\mathrm{MPam}^{1 / 2}\end{array}$ & $\begin{array}{c}\Delta \sigma_{w 0} \\
\mathrm{MPa}\end{array}$ & $\begin{array}{c}\Delta \sigma_{w 0}^{*} \\
\mathrm{MPa}\end{array}$ & $\begin{array}{c}a_{0} \\
\mu \mathrm{m}\end{array}$ & $\begin{array}{c}c_{0} \\
\mu \mathrm{m}\end{array}$ \\
\hline UFG & 2.28 & 432 & 451 & 8.14 & 6.47 \\
NCG & 3.27 & 1096 & 1143 & 2.61 & 2.07 \\
\hline
\end{tabular}

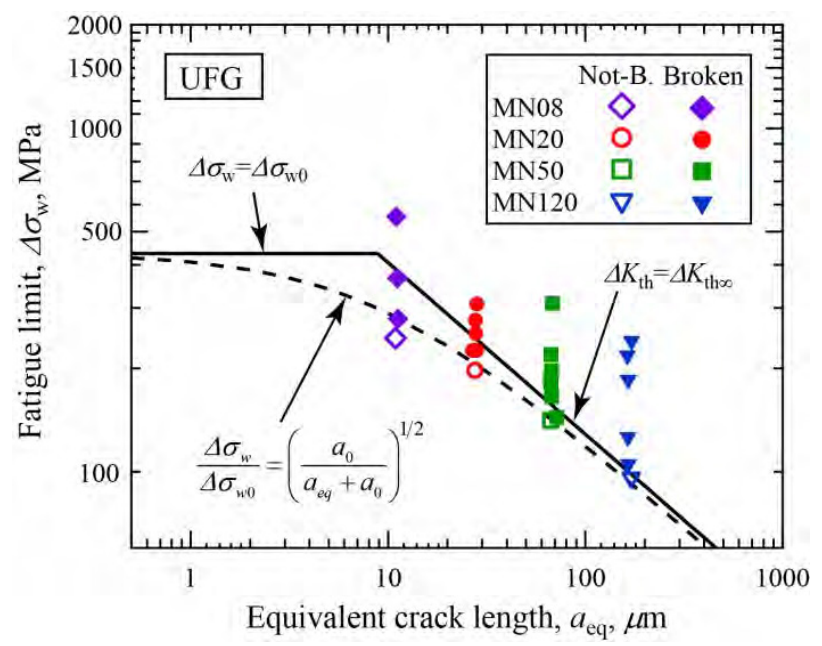

Fig. 9 Change of fatigue limit with equivalent crack length of UFG.

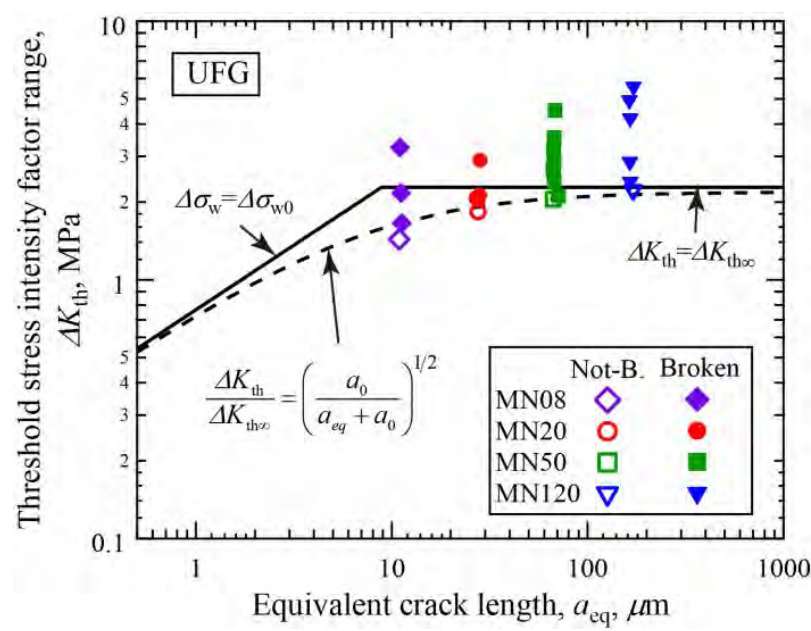

Fig. 10 Change of threshold SIF with equivalent crack size of UFG.

\subsection{Fatigue threshold of nanocrystalline films}

The crack initiation threshold SIF value, $\Delta K_{\text {th }}$, of NCG shown in Table 3 is fairly constant, indicating the notch length of $8 \mu \mathrm{m}$ means long enough to apply the constant SIF value for threshold. Using the fatigue limit, $\Delta \sigma_{\mathrm{w} 0}=$ $1096 \mathrm{MPa}$, of SM specimens multiplied by 1.043 and the $\Delta K_{\text {th }}$ of $3.27 \mathrm{MPam}^{-1 / 2}$, of MN150 of UFG, the $a_{0}$ value is calculated to be $2.61 \mu \mathrm{m}$ as shown in Table 4. This value for NCG is about three times smaller than that of $\mathrm{UFG}$, and about 150 times the grain size. A larger ratio of NCG partly comes from the fact that the fatigue limit of SM specimens is not equal to the fatigue limit of defect-free NCG as discussed later. Figures 11 and 12 show the change of the threshold stress and SIF with notch size. Both figures show a good agreement between experiments and the prediction.

The SIF value of the defect seen on the fracture surface of SM specimens was estimated from the defect area by the following Murakami's equation [11]

$$
\Delta K=0.65 \Delta \sigma \sqrt{\pi \sqrt{\text { area }}}
$$

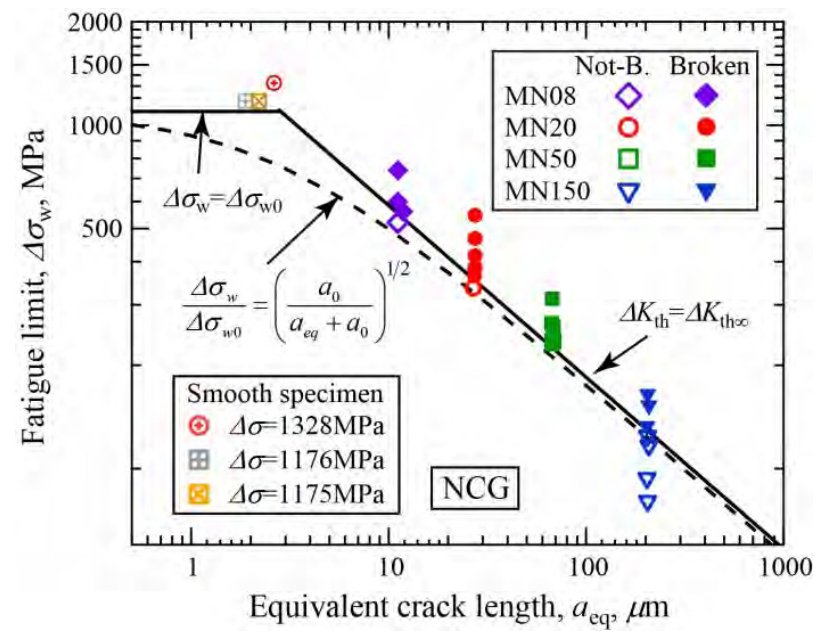

Fig. 11 Change of fatigue limit with equivalent crack length of NCG.

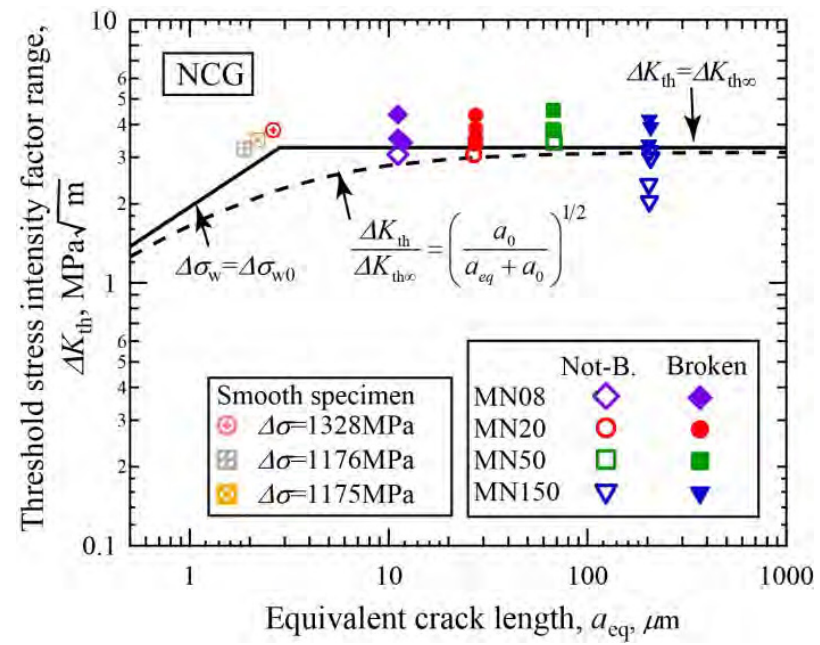

Fig. 12 Change of threshold SIF with equivalent crack length of NCG. 
The equivalent crack length is defined by

$$
\Delta K=\Delta \sigma \sqrt{\pi a_{\mathrm{eq}}}
$$

From the area of defects as shown in Fig. 8, the equivalent crack length, $a_{\text {eq }}$, is calculated by

$$
a_{\text {eq }}=(\Delta K / \Delta \sigma)^{2} / \pi=0.476 \sqrt{\text { area }}
$$

The applied stress range $\Delta \sigma$ is plotted as a function of $a_{\text {eq }}$ in Figs. 11 and 12. As seen in Fig. 11, the $\Delta K$ value of SM specimens is on and above the constant $\Delta K_{\text {th }}$ line, meaning the constant $\Delta K$ criterion is applicable to micro-sized defects due to electrodeposition for NCG.

\subsection{Discussion}

The threshold SIF for crack initiation in micro-notched specimens is different from the threshold value of long crack propagation obtained by the load-shedding method in both UFG and NCG. For UFG, the crack initiation threshold, 2.28 $\mathrm{MPam}^{-1 / 2}$, is smaller than the long crack propagation threshold $4.26 \mathrm{MPam}^{1 / 2}$. The threshold value of long cracks is the sum of crack initiation threshold plus the crack closure. The crack initiation threshold of micro-notches correspond the intrinsic threshold value. On the other hand, for NCG, the crack initiation threshold, 3.27 $\mathrm{MPam}^{-1 / 2}$, is larger than the long crack propagation threshold 2.19 $\mathrm{MPam}^{-1 / 2}$. In NCG, there is no crack closure operating, so $2.19 \mathrm{MPam}^{-1 / 2}$ is regarded as the intrinsic threshold value. The notch-tip shape might influence of initiation threshold.

In sharply notched specimens of ordinary micro-grainsized steels, non-propagating cracks are observed near the notch root even when the applied stress is below the fatigue limit [7]. The non-propagating crack is caused by the increase of crack closure with crack extension, and its length is determined by the resistance curve method proposed by Tanaka et al [10]. In the present experiments, any non-propagation cracks are not observed in both UFG and NCG. In NCG, there is no crack closure at the threshold, so non-existence of nonpropagating crack is expected. On the other hand, for UFG, the difference between the crack initiation threshold, $2.28 \mathrm{MPam}^{-1 / 2}$, and the long crack propagation threshold, 4.26 $\mathrm{MPam}^{1 / 2}$, is the amount of crack closure, $1.98 \mathrm{MPam}^{1 / 2}$. A preliminary estimate of the length on non-propagation crack based on the resistance curve method is less than $10 \mu \mathrm{m}$. If non-propagating crack exist, its length is below the resolution limit of video recording. Further detailed observation by SEM is necessary.

The length of characteristic cracks, $a_{0}$, may represent the size of the process zone of fatigue crack initiation near notch tips. The $a_{0}$ value is $8.14 \mu \mathrm{m}$ for UFG and $2.61 \mu \mathrm{m}$ for NCG. It is larger for the coarser grain sized materials, UFG, than NCG. The ratio to the grain size is 20 for UFG to 150 for NCG. For ordinary micro-sized metals, $a_{0}$ is about 10 to 20 times the grain size [7]. SEM micrographs of the fracture surface near the notch tip presented in Fig. 7 do not show any area with distinct feature corresponding to the crack initiation process. In Fig. 7(a) of UFG, the size of a semi-elliptical region is seen at the centre of the notch root, which is smaller than $a_{0}$ or $c_{0}$. A large ratio of $a_{0} / d_{0}$ for NCG may suggest that nanosized grains behave as a group of several grains in the process of fatigue crack initiation. Since the grain size of NCG is very small, even a tiny radius of the notch tip may influence the crack initiation threshold.

The fictitious crack model is applied to predict the influence of the tip radius of notches on the fatigue threshold of NCG. Figure 13 illustrates the condition of crack initiation based on the fictitious crack model. The SIF value of the notch-tip crack at the threshold is given by

$$
\Delta K_{\mathrm{th}}=1.1215 K_{t} \Delta \sigma_{w} \cdot \sqrt{\pi c_{0}} \cdot Y\left(c_{0} / \rho\right)
$$

where $\Delta \sigma_{w}$ is the fatigue limit stress, $K_{t}$ is the stress concentration factor, $c_{0}$ is the fictitious crack length, and $Y$ is the correction factor for SIF. $Y$ is a function of the ratio of crack length to the notch-tip radius $\rho$ and is often expressed as [12]

$$
Y\left(c_{0} / \rho\right)=1 / \sqrt{1+4.5\left(c_{0} / \rho\right)}
$$

The term $\left(K_{t} \Delta \sigma_{w}\right)$ means the maximum stress amplitude at the notch tip, which can be approximated by

$$
\Delta \sigma_{\max }=K_{t} \Delta \sigma_{w}=2 \Delta K_{i} / \sqrt{\pi \rho}
$$

The $\Delta K_{i}$ value mean the threshold SIF for crack initiation. By substituting the threshold SIF of long cracks 2.19 $\mathrm{MPam}^{-1 / 2}$ for $\Delta K_{\mathrm{th}}$ and the initiation threshold of MN150, $3.27 \mathrm{MPam}^{-1 / 2}$, for $\Delta K_{i}$ in Eq. (12), the ratio of $c_{0}$ to $\rho$ is obtained as

$$
c_{0} / \rho=0.15
$$

In the present experiment, the notch-tip radius is $1 \mu \mathrm{m}$, so $c_{0}$ is calculated as $0.15 \mu \mathrm{m}$. The value is about one fourteenth of the value presented in Table 4, and is nine times the grain size of NCG. It is within the range of the ratio for ordinary metals. If we calculate the fatigue limit of defect-free NCG using the following equation:

$$
\Delta \sigma_{w 0}=\Delta K_{t h} / 1.1215 \sqrt{\pi c_{0}}=2.19 / 1.1215 \sqrt{\pi c_{0}}
$$

The calculated value is $2.9 \mathrm{GPa}$, and is larger than the fatigue limit of SM specimens which have defects as the fatigue initiation site.

The influence of the tip radius of micro-notches on crack initiation will be the subject of the future study.

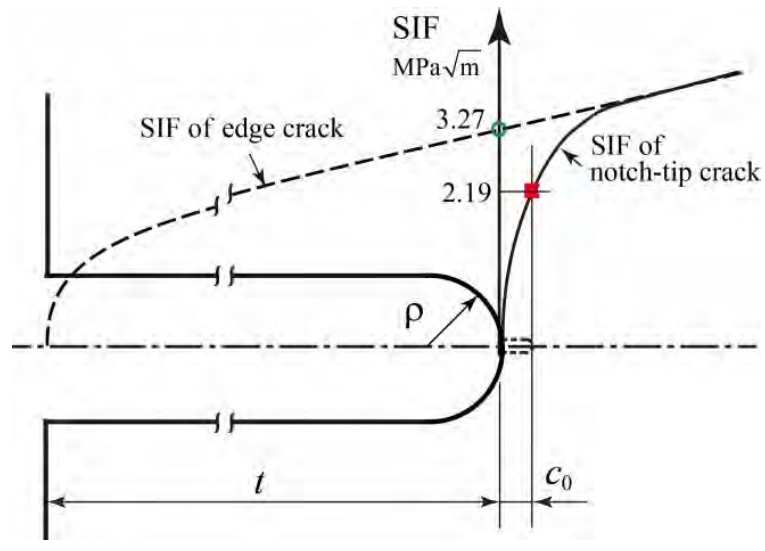

Fig. 13 SIF of fictitious crack at the notch root. 


\section{Conclusions}

The effect of micro-notches on the fatigue strength of electrodeposited nickel thin films with ultra-fine grains (UFG) of $384 \mathrm{~nm}$ in length and nano-crystalline grains (NCG) of $17 \mathrm{~nm}$ were studied using crack-like notches made by FIB. Micro-notches are $2 \mu \mathrm{m}$ wide with various depths ranging from 8 to $150 \mu \mathrm{m}$. The main results are summarized as follows:

(1) Micro-notches as small as $8 \mu \mathrm{m}$ in length did reduce the fatigue strength of both UFG and NCG, and the amount of reduction was increased with increasing depth. The fatigue strength of NCG was larger than that of UFG when compared at the same length.

(2) The fatigue limit of micro-notched specimens was determined by the initiation of fatigue crack. No non-propagating crack was observed near the notch root of specimens fatigued just below the fatigue limit.

(3) The threshold value of SIF, $\Delta K_{\text {th }}$, was decreased for short notches in UFG, while nearly constant in NCG.

(4) The fictitious crack model successfully predict the reduction of the fatigue strength as a function of notch depth. The length of fictitious crack, $a_{0}$, is smaller for NCG than UFG.

This work was supported by JSPS KAKENHI Grand Number $15 \mathrm{H} 03896$.

\section{References}

1. K. Tanaka, Y. Isokawa, H. Asano, H. KImachi, J. Soci. Mater. Sci. Jpn, 59, 313 (2010).

2. K. Tanaka, M. Sakakibara, H. Kimachi, Procedia Engng, 10, 542 (2011).

3. K. Tanaka, M. Sakakibara, H. Tanaka, S. Takeshita, H. Kimachi, J. Soci. Mater. Sci. Jpn, 61, 946 (2012).

4. K. Tanaka, Y. Koike, K. Sano, H. Tanaka, S. Machiya, T. Shobu, H. Kimachi, J. Soci. Mater. Sci. Jpn, 64, 528 (2015).

5. T. Hanlon, E. D. Tabachnikova, S. Suresh, Inter. J. Fatigue, 27, 1147 (2005).

6. Y. Murase, H. Kobayashi, K. Tanaka, H. Kimachi, Proc. 33rd Symp. Fatigue, JSMS, CD-ROM No. 41 (2016).

7. Y. Akiniwa, K. Tanaka, Trans. Jpn Soci. Mech,. Eng. A53, 393 (1987).

8. M. H. El Haddad, K. N. Smith, T. H. Topper, J. Eng. Mater.Tech., Trans. ASME, 101, 42 (1979).

9. K. Tanaka, Y. Nakai, M. Yamashita, Inter. J. Fracture, 17, 519 (1981).

10. K. Tanaka, Y. Akiniwa, Eng. Fract. Mech., 30, 963 (1988).

11. Y. Murakami, Engng. Frac. Mech., 16, 373 (1992).

12. P. Lukas, M. Klesnil, Mater. Sci. Eng., 34, 61(1978). 